\title{
Augmentative and alternative communication practices: a descriptive study of the perceptions of South African speech-language therapists
}

\author{
Shakila Dada, Yvonne Murphy, and Kerstin Tönsing \\ University of Pretoria
}

Author note

\begin{abstract}
Shakila Dada, Centre for Augmentative and Alternative Communication, University of Pretoria; Yvonne Murphy,Centre for Augmentative and Alternative Communication, University of Pretoria; Kerstin Tönsing, Centre for Augmentative and Alternative Communication, University of Pretoria
\end{abstract}

This study was supported by University of Pretoria Research Development Programme and the National Research Foundation Tutuka Grant (TTK 150708124127 and TTK 150617119597). Opinions expressed and conclusions arrived at are those of the author and are not necessarily the NRF or the University of Pretoria. The authors would like to thank all the participants.

Correspondence regarding this article should be addressed to Shakila Dada, Centre for Augmentative and Alternative Communication, University of Pretoria, Hatfield, Pretoria, 0028, South Africa. E-mail: shakila.dada@up.ac.za

Declaration of interest: The authors report no conflict of interest. The authors alone are responsible for the content and writing of this paper. 


\begin{abstract}
Speech-language therapists (SLTs) have direct contact with a wide variety of individuals who require augmentative and alternative communication (AAC) and they are therefore considered to have a primary role in the assessment, selection, and implementation of AAC symbols, techniques, aids, and strategies. Limited information is available with regard to SLTs' practices in the field of AAC, and there is a particular paucity of information about developing country contexts such as South Africa. The aim of this study was to determine how South African SLTs perceive their current AAC practices. Specifically, the study aimed to investigate SLTs' assessment and intervention practices, their choice and use of graphic symbols, and display layouts for aided AAC systems. An online survey was developed, using the Qualtrics Research Suite ${ }^{\mathrm{TM}}$ online survey software. The survey included open-ended questions (analyzed using thematic analysis) and closed questions (analyzed using descriptive statistics). The study revealed that SLTs currently use a limited variety of assessment and intervention approaches. Their current practices are informed by previous experience with various technologies and AAC systems. The results enhance the understanding of SLTs' current AAC practices and illustrate that the primary caseloads of SLTs do not appear to inform specific approaches to assessment and AAC implementation.
\end{abstract}

Keywords: Speech-language therapists; Assessment; Intervention; Perceptions; Practicebased evidence 


\section{Introduction}

Speech-Language Therapists (SLTs) play a central role in the provision of Augmentative and Alternative Communication (AAC) services. SLTs' scope of practice involves the establishment of AAC techniques and strategies, including the selection and prescription of these intervention options (American Speech and Hearing Association [ASHA], 2007; South African Speech-Language-Hearing Association [SASLHA], 2010). SLTs have direct contact with a wide variety of individuals who require AAC and are therefore considered to be primarily involved in the assessment, selection, and implementation of AAC symbols, techniques, aids, and strategies (Costigan \& Light, 2010; Thistle \& Wilkinson, 2015). This should be done in collaboration with other professionals (e.g., occupational therapists, physiotherapists, and educators) in order to attain success (Binger et al., 2012). Limited information is available with regard to SLTs' assessment and intervention practices in the field of AAC service delivery (Marvin, Montana, Fusco, \& Gould, 2003; Thistle \& Wilkinson, 2015), specifically in the South African context. Furthermore, the South African Speech-Language-Hearing Association (SASLHA) currently has no position statements to guide AAC implementation in South Africa.

South Africa, as a middle-income country, remains a largely unequal society. The impact of poverty and inequality in South Africa is visible in all sectors, including health and education - two sectors in which SLTs play an important role (Kathard \& Pillay, 2013). The number of SLTs practicing in South Africa highlights the under resourcing with an SLT-to-population ratio of 1:25,000, compared to a ratio of 1:2,500 in developed countries (Wylie, McAllister, Davidson, \& Marshall, 2013). Furthermore, approximately 67\% of the SASLHA members work in private practice in mostly urban areas, and 95\% have English and/or Afrikaans as their home language. Since the vast majority of the South African population (75\%) speak an African language 
(Kathard \& Pillay, 2013), SLTs face linguistic and cultural barriers when they provide speech language therapy and AAC services (Dada, Kathard, Tönsing, \& Harty, 2017).

Success of AAC service delivery relies heavily on the knowledge and competence levels of the clinician prescribing AAC, and on the appropriateness of techniques and devices selected (Siu et al., 2010). In addition, SLTs require research evidence that informs their clinical decisions. Concerns have, however, been raised regarding the levels of evidence-based practice and the awareness of various efficacious treatment options among the SLT population within developing countries (Wormnæs \& Malek, 2004). Practice-based evidence shares the basic tenets of evidence-based practice. However, the practice-based evidence paradigm uses an evidence base derived from routine practice settings (Barkham, Mellor-Clark, Connell, \& Cahill, 2006).

According to Newman, Kellett, and Beail (2003), “evidence-based practice and practicebased evidence could be viewed as two adjoining pieces of a jigsaw enabling the concurrent consideration of internal/statistical validity and external/naturalistic validity issues" (p. 73). Practice-based evidence provides a complementary bridge for the gap between research and practice, which promotes collaboration between service providers and academic institutions. In order to achieve this collaboration, empirical studies that identify practice-based evidence and factors that contribute to practice-based evidence need to be conducted.

Conducting research into a professional's routine practice to create evidence for future decision making is an important goal within a practice-based evidence paradigm. Furthermore, practice-based research can generate evidence to inform the practices of service providers (Lucock et al., 2003). This can enhance the quality of care provided in contexts such as South Africa, which is riddled with challenges. Gaining a better insight into routine practice settings (Newman et al., 2003) and the factors considered by SLTs in AAC implementation (Thistle \& 
Wilkinson, 2015) is an important first step in understanding their decision-making processes (Thistle \& Wilkinson, 2015). Although there are indications that AAC service provision in South Africa is increasing, for example, in special schools (Alant, 1999; Tönsing \& Dada, 2016), comprehensive information about services provided by SLTs across a variety of contexts and the factors they consider important in their practice has not been obtained.

Embedded within the AAC implementation process are the processes of assessment and intervention. The clinician has a variety of decisions to make, starting with what, when, and how to assess. Details about the assessment process, as well as trends and factors that inform an AAC assessment approach are vital in understanding appropriate and sustainable AAC recommendations and interventions (Costigan \& Light, 2010; Dietz, Quach, Lund, \& McKelvey, 2012).

Following assessment, the process of AAC implementation and intervention can be challenging and requires specific knowledge and skills. In addition, SLTs need to stay informed about relevant intervention research as well as relevant AAC technology developments, and understand the contextual issues in a country (Siu et al., 2010; Sutherland, Gillon, Yoder, 2005). Research has shown that AAC implementation and intervention processes are inconsistent, and there are no set guidelines to follow in this regard (Goldbart, Chadwick, \& Buell, 2014; Light \& McNaugthon, 2015).

In the absence of specific guidelines, SLTs' decisions when designing AAC displays may be influenced by their professional preparation and may be reflective of the SLTs' educational background and clinical experiences in implementing AAC (McFadd \& Wilkinson, 2010; Thistle \& Wilkinson, 2015). A number of specific factors have emerged as potentially playing a role in the decisions made by SLTs about system design. Familiarity with AAC systems is one possible 
influence on SLTs' decisions (Schlosser \& Raghavendra, 2004). Familiarity with different symbol sets/systems and vocabulary selection methods is important in the assessment and implementation of aided AAC systems.

The availability and affordability of assistive technology such as aided AAC systems also influences AAC practice (Van Niekerk \& Tönsing, 2015). Nonelectronic AAC systems are more frequently used in South African special schools than electronic AAC devices (Tönsing \& Dada, 2016). Similarly in a survey of SLTs in New Zealand, Sutherland, Gillon and Yoder (2005) found that low-tech communication options and sign language were the most commonly reported AAC strategies used by adults and students with complex communication needs. The recent rapid growth in mobile technologies has had implications for the field of AAC, particularly in South Africa where dedicated AAC devices are still unaffordable and/or difficult to obtain and maintain for most South Africans (Alant, 1996; Dada, Horn, Samuels, \& Schlosser, 2016). This has resulted in a shift towards recommending mobile technologies with AAC software (e.g., $\mathrm{iPad}^{1}$ (C) and Android ${ }^{2}$ TM devices with AAC software), also observed in the rest of the AAC community (McNaughton \& Light, 2013). The reasons for this shift include affordability, ease of use, increased accessibility, functionality, and interconnectivity (McNaughton \& Light, 2013). This shift has had implications for the decision-making process in terms of the selection and recommendation of these and other technologies (Goldbart et al., 2014; McNaughton \& Light, 2013; Therrien \& Light, 2016). In addition, recent provision of state funding for assistive technology (including AAC devices) in some South African provinces (Van Niekerk, Dada, Tönsing, 2017) may influence AAC technology provision.

The aim of this study was therefore to obtain information regarding current practicebased trends in AAC from the perspective of SLTs in a South African context. The intention was 
to explore their current AAC practices and the extent to which various factors influenced their practices and decisions. Specifically, practices regarding (a) AAC assessment; (b) AAC intervention, (c) selection of AAC systems and symbols, and (d) vocabulary selection and organization for aided AAC systems were explored. The field of AAC is developing rapidly and information gathered can be used to understand current practices and to guide future practicebased research in AAC in developing country contexts.

\section{Method}

\section{Participants}

Participants were practicing SLTs who were appropriately registered to practice and were currently providing AAC services. ${ }^{3}$ The online survey was available for 4 weeks and participants were recruited through multiple online methods to increase sample size and allow adequate opportunity for responding (Dillman, Smyth, \& Christian, 2009). The ethics review board of the relevant higher education institution provided approval for the study. Participant consent was obtained via an implied consent form that was embedded in the introduction to the online survey and participants were advised that continuing with the survey indicated consent.

Responses. Approximately 2,300 SLTs are registered with the Health Professional Council of South Africa. However, this number includes SLTs that are not practicing or practicing outside South Africa. Members of two email distribution lists were contacted on two occasions. An email distribution list for persons interested in AAC, as well as for SASLHA was used. The SASHLA email distribution list comprises approximately 1,200 SLTs, some of whom provide AAC services. The Centre for AAC list has approximately 1,000 subscribers who are interested in $\mathrm{AAC}$, including professionals, persons who use AAC, and family members. In addition, the University Alumni Office sent out the emails to all those individuals who had completed the 
Master's degree in $\mathrm{AAC}^{4}$ offered by the university (approximately 80). Due to the online methods to recruit participants we can estimate that approximately 2,280 recipients received the survey via email as well as 831 followers on social media platforms. However, we are unable to estimate how many of these were SLTs providing services in AAC.

A total of 183 participants initially responded to the online survey. Of these, 13 participants were excluded because they were not SLTs, seven participants were excluded as they were not registered with the Health Professions Council of South Africa, and 44 were excluded because they were not currently working in the field of AAC. A total of 121 SLTs providing AAC services eventually commenced with the survey. The survey was set up in such a way that participants were unable to skip major questions, although the survey populated some questions selectively, depending on participants' answers. For instance, those questions that pertained to assessment were automatically skipped if respondents indicated that they had not conducted any AAC assessments. Hence, there was some variation in the number of participants responding to each question. Of the 121 SLTs who commenced the survey, 54 abandoned the survey before completion perhaps due to survey fatigue. A total of 77 respondents completed the whole survey (i.e., they answered all major questions). Only the data from these respondents was analyzed.

Demographics. Table 1 provides a description of the participants. Most of the SLTs are from more resourced provinces in South Africa like Gauteng and the Western Cape. They came from various work settings, including public hospitals (33\%), private practice (22\%), universities (17\%), public schools (14\%), rehabilitation centers (13\%), private schools (10\%), private hospitals $(8 \%)$, and other settings such as nonprofit organizations (11\%). Participants' years of experience working with people in need of AAC varied - 36\% had more than 10 years' 


\section{Table 1}

Participant Descriptions

\begin{tabular}{|c|c|c|}
\hline \multicolumn{2}{|l|}{ Characteristic } & \multirow{2}{*}{ ercentage } \\
\hline Gender & Male & \\
\hline & Female & 99 \\
\hline \multirow[t]{5}{*}{ Ages } & $20-25$ years & 26 \\
\hline & $26-30$ years & 30 \\
\hline & $31-40$ years & 22 \\
\hline & $41-50$ years & 10 \\
\hline & $51-60$ years & 12 \\
\hline \multirow[t]{9}{*}{ Provinces } & Gauteng & 41 \\
\hline & Western Cape & 29 \\
\hline & KwaZulu-Natal & 6 \\
\hline & Eastern Cape & 9 \\
\hline & Free State & 4 \\
\hline & Northern Cape & 3 \\
\hline & North West & 4 \\
\hline & Mpumalanga & 3 \\
\hline & Limpopo & 1 \\
\hline \multirow[t]{3}{*}{ Home language } & English & 51 \\
\hline & Afrikaans & 42 \\
\hline & Other & 7 \\
\hline \multirow[t]{8}{*}{ Work } & Public hospital & 33 \\
\hline & Private practice & 22 \\
\hline & Universities & 17 \\
\hline & Public schools & 14 \\
\hline & Rehabilitation centers & 13 \\
\hline & Private schools & 10 \\
\hline & Private hospitals & 8 \\
\hline & Non governmental organizations & 11 \\
\hline \multirow[t]{2}{*}{ Additional training in AAC } & Masters degree in $\mathrm{AAC}$ & 14 \\
\hline & Courses or workshops in AAC & 70 \\
\hline \multirow[t]{4}{*}{ Years of experience } & 2 years or less & 9 \\
\hline & 3- 5 years & 45 \\
\hline & $6-10$ years & 9 \\
\hline & More than 10 years & 36 \\
\hline
\end{tabular}


experience, $9 \%$ had between 6 and 10 years' experience, $45 \%$ had between 3 and 5 years' experience, and 9\% had 2 years' experience or less. More than half (55\%) of the participants worked primarily with children, whereas $24 \%$ worked primarily with adults, and $21 \%$ worked with both adults and children.

\section{Survey Development}

Surveys used in the studies by Goldbart et al. (2014) and Thistle and Wilkinson (2015) were used as a basis to develop this custom online survey for the South African context. These two surveys were selected as they were recently developed and specifically focused on SLTs' practices for persons with severe disabilities and/or those in need of AAC. Four SLTs (each with at least 10 years of clinical and/or academic experience in the field of AAC) completed the pilot version of the online survey. Based on the feedback they provided, changes to the questions were made to improve the clarity of items, consolidate inconsistent terminology, refine the definition of terms used in the survey, and structure the survey more logically by reordering the questions.

Development, administration and analysis of the survey were performed using the Qualtrics online survey software (Qualtrics Research Suite ${ }^{5}$ TM survey software) and its data export feature to SPSS software. The survey comprised four sections, namely (a) biographical data, (b) AAC assessment practices, (c) AAC intervention practices, and (d) practices in the selection and use of AAC symbols and devices. The survey consisted of 52 closed questions and seven open-ended questions. Of the seven open-ended questions, four requested respondents to list different types of electronic aided AAC options they provided. One requested them to list unaided AAC methods used with their clients, one requested them to list challenges they experienced in implementing AAC, and one requested them to list additional factors influencing the recommendation of aided symbols. The closed questions comprised scaled/choice items by 
which the participants could select the option that best reflected their skills, knowledge, and practices. Closed questions were used as confirmatory questions in which the variables were already known. Formats used included a Likert scale, multiple-choice questions, matrix tables, and continuous rating scales. Various formats were used based on the response that was being elicited with Likert scales being selected when responders were required to respond with a judgment regarding an item. Continuous rating scales were used when more nuanced responses to items were required. Due to the length of the questionnaire and the nature of the questions included, variations in terms of the formats were required. The survey was available in English only and is available as supplementary online material.

\section{Survey Distribution}

A general recruitment email that described the study (with a link to the survey) and solicited participation was sent at the initial time point, and again 2 weeks later. Finally, appeals to personal contacts and postings on social media provided additional notifications regarding availability of the survey. Qualtrics online survey software hosted the web-based survey and participants could complete the survey at a convenient time and place over multiple sessions if required. The participants were given 4 weeks to complete the survey and the first 25 respondents received a complimentary voucher for an online store to the value of R100 (equivalent to about US $\$ 10$ at the time) via email.

\section{Data Analysis}

As the questions were exploratory in nature and the aim of the survey was to identify current practices and trends in implementing AAC, descriptive methods of data analysis were used. Descriptive data in the form of frequency tables were used to examine the closed questions. In order to explore the association between SLTs' home language and the language in which 
AAC therapy is provided, chi-square analysis was undertaken with Cramer's phi used as a post test to determine the associations. A one-way ANOVA was performed in order to determine whether ratings differed between SLT groups with different primary caseloads and to determine which specific groups differed from each other, using a Tukey HSD as a post hoc test.

Responses to the open-ended questions that requested respondents to list different AAC methods and/or technology were collapsed into one list per question, and duplicates were removed. The questions regarding challenges and regarding factors influencing the recommendation of aided symbols were coded for common themes following Braun and Clarke's method (2006). The first and second author independently identified themes and subthemes by reading each response and listing commonly repeated responses and identifying similarities and differences in the responses. Data saturation was reached when no new themes became apparent. The third author then checked the first and second authors' codes. Refinement of the themes and subthemes occurred thereafter during a cycle of consensus coding between all three authors. Redundant themes were excluded and similar themes were combined during a cycle of consensus coding. Commonly repeated themes and subthemes were listed.

\section{Results}

\section{Languages in which AAC therapy is provided}

Table 2 illustrates the languages in which AAC therapy is provided per home language group. It is evident from the table that the majority of the SLTs provide AAC intervention in English and Afrikaans. This is not surprising, since these two languages were the home languages spoken by $93 \%$ of the respondents. All SLTs who had English and Setswana as home languages provided therapy in their home language. None of the SLTs who had isiNdebele or Tshivenda as their home language provided therapy in their home language, but the small 
Table 2

Percentage Distribution of Languages in Which AAC Therapy is Provided per Home Language Group

\begin{tabular}{|c|c|c|c|c|c|c|c|c|c|c|}
\hline \multirow{2}{*}{$\begin{array}{l}\text { SLT home language } \\
\text { ( } n \text { given in } \\
\text { parentheses) }\end{array}$} & \multicolumn{10}{|c|}{ Languages in which AAC Therapy is provided } \\
\hline & English & Afrikaans & isiNdebele & isiXhosa & isiZulu & Sepedi & Sesotho & Setswana & Tshivenda & Xistsonga \\
\hline English $(n=39)$ & $100 \%$ & $44 \%$ & 0 & $25 \%$ & $18 \%$ & $5 \%$ & $7 \%$ & $2 \%$ & $2 \%$ & $2 \%$ \\
\hline Afrikaans $(n=32)$ & $90 \%$ & $80 \%$ & 0 & $20 \%$ & 0 & $4 \%$ & $10 \%$ & $8 \%$ & 0 & 0 \\
\hline isiNdebele $(n=1)$ & $100 \%$ & 0 & 0 & $100 \%$ & $100 \%$ & $100 \%$ & $100 \%$ & $100 \%$ & 0 & 0 \\
\hline Setswana $(n=1)$ & $100 \%$ & 0 & 0 & 0 & $100 \%$ & $100 \%$ & $100 \%$ & $100 \%$ & 0 & 0 \\
\hline Tshivenda $(n=1)$ & $100 \%$ & 0 & 0 & 0 & 0 & 0 & 0 & $100 \%$ & 0 & 0 \\
\hline
\end{tabular}


number of respondents in these groups probably had an influence. Of the SLTs who spoke Afrikaans, $80 \%$ provided therapy in Afrikaans. When exploring the relationships between the SLTs' home languages and additional languages in which AAC therapy was provided (i.e., languages other than the home language), a medium clinically significant relationship (Field, 2013) was found between having English as a home language and also providing AAC therapy in Afrikaans $\chi^{2}(2, N=69)=18.958, p=.002, \Phi_{\text {Cramer }}=.401$ Furthermore, a small (Field, 2013) clinically significant relationship was found between having Engish or Afrikaans as a home language and providing AAC therapy in isiXhosa, $\chi^{2}(2, N=91)=4.310, p=.506, \Phi_{\mathrm{Cramer}}=$ .191 , as $24.6 \%$ and $20 \%$ of SLTs with English and Afrikaans as their home language respectively also reported providing AAC therapy in isiXhosa. There were no other significant relationships between the SLTs' home languages and the languages in which AAC therapy was provided.

\section{Assessment in AAC}

Overall, 97\% (75 of 77) of the participants indicated that they conduct AAC assessments. Of these 75 respondents, $74 \%$ (55) indicated that they use a combination of standardized tests as well as functional and authentic assessments (full range of strategies used to determine abilities in real life situations; Lloyd, Fuller, \& Arvidson, 1997) in their assessment approach, with $21 \%$ (16) using only functional assessments and 5\% (4) using observations in natural settings. Table 3 illustrates the means and standard deviations (on a continuous scale from 0 - not important - to 100 - always important) assigned to various sources considered important in informing the assessment process according to SLTs' primary caseload. Resources readily available were rated of highest importance for SLTs with a primary caseload of children $(M=84.46, S D=16.48)$, adult caseload $(M=90.55, S D=11.51)$, and mixed caseloads $(M=82.58, S D=24.38)$. There 
Table 3

Rating of Importance of Various Sources in Informing Assessment Approaches as per SLTs Primary Caseload

\begin{tabular}{|c|c|c|c|c|}
\hline $\begin{array}{l}\text { Rate how each of the following } \\
\text { informs your assessment approach }\end{array}$ & Group & $M$ & $S D$ & $p$-value \\
\hline \multirow{3}{*}{$\begin{array}{l}\text { Research evidence: Published } \\
\text { research evidence }\end{array}$} & Children & 73.78 & 18.40 & \multirow{3}{*}{0.23} \\
\hline & Adults & 68.24 & 24.19 & \\
\hline & Equal caseload of both & 65.04 & 24.64 & \\
\hline \multirow{3}{*}{$\begin{array}{l}\text { Resources readily available to you } \\
\text { as clinician (e.g. web resources, } \\
\text { paper-based resources, etc) }\end{array}$} & Children & 84.46 & 16.48 & \multirow{3}{*}{0.31} \\
\hline & Adults & 90.55 & 11.51 & \\
\hline & Equal caseload of both & 82.58 & 24.38 & \\
\hline \multirow{3}{*}{$\begin{array}{l}\text { Clinical expertise: The views of } \\
\text { other professionals }\end{array}$} & Children & 78.89 & 16.31 & \multirow{3}{*}{0.17} \\
\hline & Adults & 75.30 & 17.13 & \\
\hline & Equal caseload of both & 69.17 & 30.44 & \\
\hline \multirow{3}{*}{$\begin{array}{l}\text { Personal clinical expertise: } \\
\text { Familiar theory/approach that has } \\
\text { worked for you before }\end{array}$} & Children & 80.39 & 16.29 & \multirow{3}{*}{0.68} \\
\hline & Adults & 78.76 & 24.34 & \\
\hline & Equal caseload of both & 76.00 & 23.80 & \\
\hline \multirow{3}{*}{$\begin{array}{l}\text { Websites: Including google } \\
\text { searches }\end{array}$} & Children & 55.65 & 28.50 & \multirow{3}{*}{0.42} \\
\hline & Adults & 60.35 & 26.98 & \\
\hline & Equal caseload of both & 64.63 & 27.80 & \\
\hline
\end{tabular}

Note. Ratings were given based on a sliding scale from 0 (not important) to 100 (always important).

$* p \leq 0.05$ 
were no statistically significant differences in the average ratings according to the primary caseload type.

In addition, the respondents were asked to rate the importance of including certain areas in an AAC assessment by using a continuous rating scale from 0 (not important) to 100 (extremely important). Table 4 illustrates the means and standard deviations for the areas included in an AAC assessment. Ratings were generally high (means larger than 80 for all three caseload groups) for communication of basic needs, choice making, and preferences of the individual who requires AAC.

\section{AAC Implementation}

Of the initial 77 respondents, 94\% (72) indicated that they conducted AAC intervention. SLTs provided AAC intervention to individuals with a variety of diagnoses, including developmental disabilities (71\%), autism spectrum disorder (67\%), aphasia (56\%), traumatic brain injuries (51\%), developmental apraxia of speech (47\%), temporary users of AAC (39\%), motor neuron disease (33\%), and other diagnoses (19\%). This last group included acquired apraxia of speech, dysarthria and speech difficulties following laryngectomy, and trachea insertion with an inability to use speech valves.

Respondents were also asked to indicate whether they worked in a team when implementing AAC. Overall, $62(86 \%)$ of the 72 who conducted AAC interventions indicated that they worked in teams. Of these respondents $(n=62), 89 \%$ indicated that the team members included family members and $89 \%$ also indicated that the person who uses AAC was part of the team. Other team members were occupational therapists (76\%), teachers (52\%), physiotherapists (46\%), nurses (26\%), doctors (19\%), social workers (13\%), and others (22\%) including facilitators, caregivers, and psychologists. 
Table 4

Rating of Importance of Areas of Assessment as per SLTs Primary Caseload

\begin{tabular}{|c|c|c|c|c|}
\hline $\begin{array}{l}\text { Rate how each of the following informs } \\
\text { your assessment }\end{array}$ & Group & $M$ & $S D$ & $\begin{array}{c}p \text { - } \\
\text { value }\end{array}$ \\
\hline \multirow[t]{3}{*}{ Communication of basic needs } & Children & 92.70 & 17.71 & .26 \\
\hline & Adults & 95.86 & 8.56 & \\
\hline & Equal caseload of both & 88.04 & 23.25 & \\
\hline \multirow[t]{3}{*}{ Choice making } & Children & 90.77 & 16.73 & 0.16 \\
\hline & Adults & 94.00 & 10.18 & \\
\hline & Equal caseload of both & 84.166 & 23.96 & \\
\hline \multirow{3}{*}{ Sorting } & Children & 67.49 & 29.28 & 0.85 \\
\hline & Adults & 64.29 & 27.97 & \\
\hline & Equal caseload of both & 64.58 & 19.60 & \\
\hline \multirow{3}{*}{ Cause and Effect } & Children & 84.05 & 22.74 & 0.36 \\
\hline & Adults & 75.71 & 26.89 & \\
\hline & Equal caseload of both & 83.96 & 22.45 & \\
\hline \multirow[t]{3}{*}{ Imitation } & Children & 73.09 & 27.38 & 0.14 \\
\hline & Adults & 59.19 & 30.48 & \\
\hline & Equal caseload of both & 72.29 & 25.69 & \\
\hline \multirow[t]{3}{*}{ Daily routines } & Children & 85.02 & 20.37 & 0.21 \\
\hline & Adults & 87.71 & 15.90 & \\
\hline & Equal caseload of both & 77.08 & 28.25 & \\
\hline \multirow{3}{*}{$\begin{array}{l}\text { Preferences of individuals who require } \\
\text { AAC }\end{array}$} & Children & 85.82 & 19.06 & 0.63 \\
\hline & Adults & 90.29 & 17.14 & \\
\hline & Equal caseload of both & 84.83 & 25.80 & \\
\hline \multirow[t]{3}{*}{ Preferences of family and significant others } & Children & 81.5 & 23.20 & 0.60 \\
\hline & Adults & 86.19 & 20.98 & \\
\hline & Equal caseload of both & 72.29 & 25.41 & \\
\hline \multirow[t]{3}{*}{ Communication Environments and partners } & Children & 83.98 & 23.00 & 0.37 \\
\hline & Adults & 85.52 & 18.49 & \\
\hline & Equal caseload of both & 76.88 & 26.38 & \\
\hline \multirow[t]{3}{*}{ Representational abilities } & Children & 67.48 & 27.60 & 0.79 \\
\hline & Adults & 63.00 & 29.38 & \\
\hline & Equal caseload of both & 63.71 & 35.91 & \\
\hline \multirow[t]{3}{*}{ Device trials } & Children & 82.30 & 21.89 & 0.65 \\
\hline & Adults & 77.76 & 17.07 & \\
\hline & Equal caseload of both & 83.38 & 24.45 & \\
\hline
\end{tabular}

Note. Ratings were given based on a sliding scale from 0 (not important) to 100 (always important).

$* p \leq 0.05$ 
With respect to the inclusion of family members and the person who uses AAC in AAC intervention teams, SLTs rated the importance of their involvement higher than their observed involvement in the AAC intervention process. The importance of family involvement was rated at $96 \%$ on a continuous rating scale from 0 (not important) to 100 (extremely important) and the involvement of the person who uses AAC at $93 \%$. Furthermore, $83 \%$ of the respondents indicated that they refer to other professionals. Included in this referral system are AAC specialists at a university-based center; AAC suppliers in the country; and other professionals such as audiologists, dieticians, ear, nose, and throat specialists, eye specialists, occupational therapists, pediatric neurologists, and psychologists.

Participants also rated (on a continuous scale from 0 (not important) to 100 (always important) the importance of various factors in informing their AAC intervention approach. A one-way ANOVA was performed in order to determine whether ratings differed between SLTs groups with different primary caseloads. Table 5 illustrates the results. A statistically significant interaction between the active involvement of the family members in the AAC intervention process and primary caseload was found, $F(3,88=4.45), p=0.014$. Post hoc comparisons using the Tukey HSD indicated that the mean score for the SLTs with an equal load of children and adults $(M=90.35, S D=13.75)$ differed significantly and were more likely to involve family members in AAC interventions when compared to those with a primary caseload of children $(M$ $=96.06, S D=6.46)$ or adults only $(M=97.60, S D=5.05)$. However, there was no statistical difference between the ratings of SLTs with a primary caseload of children and those with a primary caseload of adults.

Implementation challenges. Participants were asked to rate the frequency with which they experienced various challenges in AAC interventions on a continuous rating scale from 0 
Table 5

Rating of Importance of Various Sources that Influence Intervention Approach as per SLT's Primary Caseload

\begin{tabular}{|c|c|c|c|c|}
\hline $\begin{array}{l}\text { Rate how each of the following } \\
\text { informs your intervention approach }\end{array}$ & Group & $M$ & $S D$ & $p$-value \\
\hline \multirow[t]{3}{*}{ Websites: Including google searches } & Children & 61.21 & 28.16 & 0.611 \\
\hline & Adults & 59.35 & 24.77 & \\
\hline & Equal caseload of both & 67.15 & 24.09 & \\
\hline \multirow{3}{*}{$\begin{array}{l}\text { Available resources: Resources readily } \\
\text { available to you as clinician }\end{array}$} & Children & 85.69 & 16.72 & 0.759 \\
\hline & Adults & 88.80 & 12.26 & \\
\hline & Equal caseload of both & 87.40 & 19.43 & \\
\hline \multirow{3}{*}{$\begin{array}{l}\text { Research evidence: Published research } \\
\text { evidence }\end{array}$} & Children & 76.15 & 17.64 & 0.552 \\
\hline & Adults & 71.65 & 27.35 & \\
\hline & Equal caseload of both & 78.85 & 22.73 & \\
\hline \multirow{3}{*}{$\begin{array}{l}\text { Clinical expertise: The views of other } \\
\text { professionals }\end{array}$} & Children & 78.89 & 14.78 & 0.897 \\
\hline & Adults & 76.95 & 15.19 & \\
\hline & Equal caseload of both & 79.20 & 24.32 & \\
\hline \multirow{3}{*}{$\begin{array}{l}\text { Personal clinical expertise: Familiar } \\
\text { theory/approach that has worked for } \\
\text { you before }\end{array}$} & Children & 83.09 & 13.30 & 0.679 \\
\hline & Adults & 80.10 & 20.86 & \\
\hline & Equal caseload of both & 79.50 & 24.32 & \\
\hline \multirow{3}{*}{$\begin{array}{l}\text { Consultation with the individual who } \\
\text { uses AAC }\end{array}$} & Children & 93.31 & 11.14 & 0.655 \\
\hline & Adults & 95.50 & 11.75 & \\
\hline & Equal caseload of both & 91.50 & 20.30 & \\
\hline \multirow{3}{*}{$\begin{array}{l}\text { Active involvement of family } \\
\text { members or significant others in the } \\
\text { AAC intervention }\end{array}$} & Children & 96.06 & 6.46 & $0.014 *$ \\
\hline & Adults & 97.60 & 5.05 & \\
\hline & Equal caseload of both & 90.35 & 13.75 & \\
\hline
\end{tabular}

Note. Ratings were given based on a sliding scale from 0 (not important) to 100 (always important).

$* p \leq 0.05$ 
(never a challenge) to 100 (always a challenge). SLTs identified funding as a major challenge to AAC implementation (mean rating $86 \%$ ), followed by availability of AAC devices (80\%), time constraints (77\%), staying abreast of developments in AAC (66\%), low expectations for the individual who uses AAC (64\%), and slow progress by the individual using AAC (62\%). Collaboration with other team members was rated to be a challenge fairly often (53\%).

Other themes identified in the open-ended question as challenges included (a) lack of training that is evidence based, current, assists with feature matching (process by which a person who requires AAC current and projected needs are matched to the AAC symbols and devices; Lloyd et al., 1997), and that keeps therapists up to date with the latest technologies; (b) lack of support from family members, teachers, other therapists, and professionals in implementing AAC; (c) lack of adaptation of the curriculum at school to accommodate the child who uses AAC; (d) difficulties in creating low-technology options that are versatile and generative in nature; (e) limited familiarity and availability of AAC systems/devices in other languages; and (f) a lack of trial equipment that SLTs could use with a potential candidate for AAC.

AAC systems. Of the 72 respondents who indicated that they provided AAC intervention, $62(86 \%)$ indicated that they primarily recommended a combination of both aided (methods of expression that use external items such as communication boards, speech-generating devices, etc.) and unaided AAC systems (methods of expression that do not use external items, such as gestures, facial expressions), with six respondents (8\%) recommending primarily aided AAC systems and four (6\%) recommending primarily unaided AAC systems. The 66 respondents who recommended unaided systems (either exclusively or in addition to aided systems) were asked to rate the frequency with which they recommended certain forms of unaided AAC on a 5-point Likert scale, ranging from 1 (never) to 5 (always). Participants tended 
to recommend less formal unaided systems more frequently, with average mean ratings of 4.08, 4.06, and 3.55 assigned to vocalizations, natural gestures, and facial expressions respectively ( $S D$ $=0.91,0.81$, and 1.23, respectively). More formal systems such as South African Sign Language $(M=2.36, S D=1.14)$ and Makaton $(M=2.12, S D=1.26)$ were not recommended as frequently. Other unaided AAC systems that were listed were eye blinking and local signing in rural communities.

Regarding aided AAC intervention, $94 \%$ of 68 respondents indicated that they recommended nonelectronic dedicated AAC systems (e.g., communication boards), 57\% electronic non-dedicated AAC systems (e.g., tablet with AAC application), and 38\% electronic dedicated AAC devices (e.g., GoTalk ${ }^{6 \mathrm{TM}}$ ). Respondents listed the names of the devices that they recommended. These included various GoTalk devices, because they are easily available through state funding; as well as BIGmack ${ }^{7 \mathrm{TM}}$, Big Point $^{8 \mathrm{TM}}$, iTalk $2^{7 \mathrm{TM}}$, Smart$^{\mathrm{T}}$ Talk $^{9}{ }^{\mathrm{TM}}$, Step by Step $^{7 \mathrm{TM}}$, Talking Bricks ${ }^{7 \mathrm{TM}}$, and Vmax ${ }^{10} \mathrm{TM}$. Furthermore, the SLTs were asked to rate, on a 5point Likert scale from 1 (never) to 5 (always), how frequently their clients used these devices in the therapy session $(M=3.33, S D=1.09)$ and outside the therapy situation $(M=2.74, S D=$ $0.75)$.

With regard to electronic non-dedicated AAC systems, the $57 \%$ of respondents who recommended these systems were asked to indicate which operating systems these run on $-65 \%$ indicated Android, 53\% indicated $\operatorname{iOS}^{1}$ C (operating system for iPads, iPhones ${ }^{1}$ C), and iPods ${ }^{1}$ (C)), and $31 \%$ indicated Windows ${ }^{11 \mathrm{TM}}$. Respondents listed $20 \mathrm{iOS}$ apps, five Android apps, and eight Windows-based software systems. In addition, many of the respondents stated that although there is a wider variety of AAC applications running on iOS, Android devices are generally more affordable. 
Factors influencing selection of AAC software. The respondents who recommended electronic non-dedicated AAC systems were also asked to rate the degree to which various factors influenced the selection of software (apps and programs) for these systems on a 4-point Likert scale, ranging from 1 (not at all), to 4 (very much so). The factors influencing recommendation were affordability $(M=3.7, S D=0.6)$, ease of operating the application $(M=$ $3.8, S D=0.4)$, how easily the application could be obtained $(M=3.6, S D=0.6)$, ease of operating the application $(M=3.6, S D=0.7)$, and ease with which significant others could be trained to operate the application $(M=3.8, S D=0.4)$. Feature matching and the iconicity of the symbols used in the application both received a mean rating of $3.7(S D=0.7)$, while the ability of the application to support language development and its pragmatic functions were rated at 3.4 $(S D=0.8)$ and $3.2(S D=0.8)$, respectively. Somewhat lower average ratings were assigned to previous clinical experience with the application $(M=3.1, S D=0.8)$, ability of the application to allow for digital recording $(M=3.0, S D=0.9)$, availability in other languages $(M=3.0, S D=$ $0.9)$, the fact that the application is based on published research $(M=2.9, S D=0.8)$, and the fact that the application has a synthetic voice $(M=2.7, S D=0.9)$. In response to two questions, participants listed all the Windows-based AAC software as well as all the Android- and iOSbased software and applications they recommended. (See appendix for a list of the AAC apps and software.)

Aided Display formats. The SLTs who recommended electronic AAC systems were asked to rate the frequency with which they used various display formats on a 5-point Likert scale ranging from 1 (never) to 5 (always). The results varied considerably for each type of display. Grid displays were used most often, with an average rating of $3.28(S D=1.29)$, and static/fixed displays were used most of the time $(M=3.15, S D=1.41)$. The mean ratings for 
hybrid/mixed displays (i.e., displays that have both static and dynamic elements to them) and dynamic displays (displays with symbols that, when pressed, change the set of symbols that is displayed $)$ indicated that these displays were used less often with average ratings of $2.08(S D=$ $1.19)$ and $2.14(S D=1.17)$ respectively. Respondents indicated that, on average, they used visual scene displays sometimes $(M=2.38, S D=1.14)$.

Vocabulary. The respondents were asked to indicate how they primarily determined vocabulary to be included in aided AAC systems. Altogether $86 \%$ of the respondents indicated that they used ecological/environmental inventories (i.e., a list of communication demands and opportunities related to the environment of the person who needs AAC). Other means of determining the vocabulary included family preferences (73\%), a list of words the person in need of AAC attempted to communicate (69\%), context-specific conversations (53\%), core vocabulary lists (50\%), and word lists of typically developing peers (29\%).

The primary focus for $54 \%$ of the respondents (39 of 72) in respect of initial vocabulary selection was reported as core vocabulary (words used frequently and in a variety of situations). Only $3 \%$ of the respondents initially focused on fringe vocabulary (words which are more situation specific), whereas $43 \%$ indicated that both core and fringe were selected for the initial vocabulary. The respondents were asked to indicate how they primarily organized their vocabulary and $86 \%$ used category-based organization, $7 \%$ organized it based on parts of speech, and $8 \%$ indicated other (including conversation starters and a combination of the above). None used an alphabet-based organization.

Aided symbol types. The respondents were asked to indicate, on a 5-point Likert scale ranging from 1 (never), to 5 (always) how often they recommended various aided symbols. They were also asked to rate how often certain factors influenced their selection of aided symbols. The 
majority indicated that they recommended Picture Communication Symbols $(M=3.74, S D=$ 0.96), color photographs $(M=3.74, S D=0.96)$, objects $(M=2.99, S D=1.04)$, tangible symbols $(M=2.75, S D=1.01)$, black-and-white photographs $(M=2.68, S D=1.07)$, SymbolStix $(M=$ $1.53, S D=0.89)$, Widget $(M=1.66, S D=1.0)$, Blissymbols $(M=1.44, S D=0.76)$, Minspeak $(M=1.34, S D=0.73)$, and Makaton $(M=1.34, S D=0.73)$.

Regarding factors that influenced their selection of aided symbols, the factor receiving the highest rating was the availability of resources $(M=4.56, S D=0.63)$, followed by ease of learning $(M=4.42, S D=0.67)$, and previous clinical experience $(M=3.77, S D=0.85)$. Other factors were skills of the person who used AAC $(M=4.17, S D=0.81)$, family views $(M=3.75$, $S D=1.06)$, peer recommendation $(M=3.38, S D=0.97)$, published research $(M=3.01, S D=$ $0.96)$, and access to social media $(M=2.04, S D=1.21)$.

\section{Discussion}

The present survey is the first study to investigate AAC practices of South African SLTs. Service provision in the South African health and education sectors is still characterized by widespread inequalities (Pillay \& Kathard, 2015). The finding that a considerable number of respondents provided AAC services in public health or education settings is therefore encouraging, as it suggests that services are reaching at least some members of historically disadvantaged and still marginalized groups (people from African-language backgrounds and of a lower socioeconomic status). This is contrary to the perception that AAC services are typically provided in the private sector where there are more resources and specialized services (Kathard \& Pillay, 2013; Light \& McNaughton, 2015).

At the same time, AAC services were mostly provided in English and most respondents spoke English or Afrikaans as their home language. This contrasts starkly with South African 
demographics, which shows that about $75 \%$ of the South African population has one of the nine African official languages as their home language (Kathard \& Pillay, 2013). While service recipients in the private sector are typically white and from English or Afrikaans language backgrounds, linguistic diversity among service recipients in the public sector is typically high (Kathard et al., 2011). This suggests that many persons and families receive AAC intervention in a language other than their home language, and that - contrary to what is regarded as best practice in communication intervention (Soto \& Yu, 2014) - the client's home language is not always promoted via AAC. The need for urgent transformation within the profession in South Africa has been highlighted (Pillay \& Kathard, 2015). A radical shift in training curriculum focusing on SLTs from diverse linguistic backgrounds is necessary to address the failure to provide services particularly to the majority Black African population in South Africa (Pillay \& Kathard, 2015).

The finding that $85 \%$ of respondents worked in a team is positive, as AAC is an interdisciplinary field that requires a team approach to ensure holistic and sustainable intervention (Alant, 2005; Beukelman \& Mirenda, 2013). Teamwork was also indicated as the least challenging aspect of AAC service provision. The majority of respondents (71\%) indicated that they use a combination of AAC assessment approaches. These results suggest that SLTs are moving away from conventional standardized assessment methods to a more functional means of assessment, as has been reported in other contexts (Costigan \& Light, 2010; Dietz et al., 2012).

Respondents also indicated that they recommended AAC for clients with a variety of diagnoses. It is clear that they saw AAC to have wide application to various populations, congruent with research evidence (Koul \& Corwin, 2011). 
Respondents reported a relatively limited influence of research evidence to inform assessment and intervention practices. In contrast, available resources and clinical expertise of other professionals were reported to influence AAC services more frequently. Various factors have been reported to limit the incorporation of research evidence into AAC practice. Research evidence for various aspects of AAC service delivery is still extremely limited, and practitioners may simply not have any evidence that could guide the particular clinical decision they have to make for a particular client (Goldbart et al., 2014). Research evidence may also be difficult to obtain due to a lack of appropriate continuous professional development opportunities and/or lack of access to peer-reviewed journal articles (Schlosser, Wendt, Angermeier, \& Shetty, 2005). Also, not all elements of evidence-based research may generalize or be clearly applicable in South African contexts that are characterized by sociolinguistic diversity, lack of resources, and lack of trained professionals.

The importance assigned to various factors informing AAC assessment and implementation did not differ significantly (for most factors) between SLTs with a primary caseload of children, those with a primary caseload of adults, and those with mixed caseloads. Family involvement was considered slightly less important for informing intervention for SLTs with mixed caseloads. It is possible that SLTs with mixed caseloads tended to practice in settings where they did not have the luxury of specializing on either adults or children, due to, for example, personnel shortages. Such less supportive contexts may have made family involvement more difficult, possibly due to time constraints.

The challenges faced in AAC intervention that were rated highest included funding, availability of AAC devices, and time constraints. In South Africa, habilitation and rehabilitation services (including assistive technology) are supposed to be provided both through the public 
school system (for school-going children - typically between the ages of 6 and 18 years) as well as the public health system (for persons who are not within the public school system). Guidelines and mandates for AAC system provision through the public health and education systems are contained in legislation and policy documents (Department of Education, 2007, 2010; Department of Health, n.d.), but uniform procedures for assessment, procurement, and effectiveness monitoring are not in place. In contrast, the procedures for obtaining public health funding for SGDs in contexts like the USA seem to be clearly outlined and provision of SGDs to children who need them is described as 'routine' (Golinker, 2009, p. 64).

Although about $18.1 \%$ of the South African population (typically the wealthiest sector) have private medical insurance (Business Tech, 2016), the acquisition of AAC devices is often not covered, and the number of intervention sessions is typically limited (Van Niekerk \& Tönsing, 2015). Although mobile technology options are less pricy, they are still difficult to afford for many South Africans, since 53.8\% of the population live in poverty (Nicolson, 2015). Clear pathways for the provision of AAC systems through state institutions as well as private medical insurance are urgently needed in South Africa. In order for funding to reach the maximum number of clients, non-dedicated devices should also be considered as options.

Limited funding of AAC devices has previously also been reported in more affluent contexts, such as New Zealand (Sutherland et al., 2005) and Hong Kong (Siu et al., 2010). In Hong Kong, state funding reportedly covered only $26 \%$ of AAC devices provided in preschools (Siu et al., 2010). However, funding is typically even more challenging in developing countries ((Borg, Larsson, \& Östergren, 2011; Mukhopadhyay \& Nwaogu, 2009; Visagie et al., 2016), and 
estimations suggest that only 5-15\% of persons in need of assistive technology in developing countries actually receive it (World Health Organisation, 2017).

In spite of limited funding, $96 \%$ of the respondents recommended aided systems, either exclusively (9\%) or in combination with unaided systems (87\%). Although unaided systems such as keyword signing typically require less funding, various drawbacks (such as the motor skills required and the need for all partners to learn the signs) may make then unsuitable or limited for many clients. With regard to aided AAC devices, the fact that the majority of respondents (94\%) recommended the use of non-electronic AAC systems links well with the main challenge funding. A higher recommendation rate of electronic non-dedicated AAC devices (59\%) may also be related to funding limitations, as these devices are comparatively more cost effective than electronic dedicated AAC devices (recommended by $38 \%$ of respondents). Dedicated AAC devices may also be less easily available and more complicated to maintain, as manufacturers are not based locally (McNaughton \& Light, 2013).

The respondents who recommended electronic non-dedicated AAC systems indicated that these run on Android systems most of the time (61\%). This resonates well with the affordability factor, which SLTs rated as the factor that had the largest effect on recommendations. Many of the respondents indicated that although they felt iOS systems have a wider variety of AAC applications to offer, Android devices are more cost effective. Respondents also indicated that the cost of the application is a factor that influenced their recommendations, and that free applications were more popular. Affordability was considered more frequently than published research in recommending AAC applications, which once again leads to questions regarding the availability and application of research evidence in practice. 
Factors that influence vocabulary selection for aided AAC systems are under constant scrutiny. According to the respondents, the factors that primarily determined vocabulary were ecological inventories, family preferences, and a list of words that the individual with little or no functional speech attempted to communicate. This relates well to the shift from conventional assessments to authentic and functional assessment methods. The findings are congruent with other studies that found that the initial vocabulary focus is mainly core vocabulary $(56 \%)$ and vocabulary is predominantly organized mainly by semantic category (Binger \& Light, 2007; Thistle \& Wilkinson, 2015).

With regard to aided symbol recommendations, respondents indicated that they recommended Picture Communication Symbols and color photographs "always", and objects and tangible symbols "most of the time." It could be argued that this depends mainly on the availability of resources and ease of learning (Dada et al., 2013), because these were the two factors rated as the most important influences in AAC aided symbol recommendations.

\section{Limitations of the Study}

The limitations of the study include the online recruitment strategies that made it difficult to determine a true response rate. The size of the population of SLTs involved in AAC service delivery is not known, as there is not central register for these professionals. Additionally, although the inclusion criteria required a minimum of 1 year of experience providing AAC services, individual experience could have differed vastly. In addition, the number of clients in need of AAC on the SLTs' caseloads was not used as an exclusion criterion, once again adding to the variety of individual experience.

As many of the responders indicated that they had additional training in AAC and many had 3 or more years' experience with services to persons that require AAC, it is possible that the 
sample may have tended to include SLTs that have a specific interest in AAC. There may have been non-responders who implement AAC in their practice, but have less training, interest, or experience who elected not to participate in the study. Also, of the 121 eligible SLTs who commenced the survey, only 77 completed it. This may have been caused by survey fatigue. Hence, the results of the study should be interpreted with caution and with specific reference to those that participated in the study. This low response rate is a limitation of the study and future research should consider personalized emails to request completion of surveys. Furthermore, there were no additional methods used to triangulate self-report findings with observations of AAC assessments/implementation conducted by responders.

Responders might have felt that this task was asking them to justify their professional actions, introducing the possibility of Hawthorne effect which may result in socially desirable responses that lead to behaviors in line with these expectations (McCambridge, Witton, \& Elbourne, 2014)

Although responses in the current survey may have reflected a social desirability effect, the self-administered and anonymous nature of the survey may have reduced the likelihood of such bias.

\section{Conclusion}

The present survey is the first study to investigate the perceptions of South African SLTs regarding their current practices in AAC. AAC is developing rapidly and it is essential to document how AAC services are provided and what is being implemented. The information gathered raises awareness about the trends, challenges, and perceptions of SLTs who implement AAC in the South African context. The results suggested that various factors influenced their practices - factors related both to the South African sociolinguistic and geopolitical context, as 
well as to international developments. These factors include results suggest that contextual factors and constraints (e.g., lack of funding and multilingual contexts), as well as international developments (e.g., mobile technology trends) influence SLTs' AAC practices. These findings can assist in encouraging practitioners and researchers to critically reflect on current practices and to identify and systematically investigate factors that could improve current service delivery of AAC in South Africa. Further research could identify barriers to the use of research evidence to inform practice and explore strategies to generate and disseminate contextually relevant and clinically usable evidence on efficacious AAC assessment and intervention practices. While availability and affordability of AAC devices are factors that cannot be ignored in AAC service delivery, these factors run the risk of dictating practices without sufficient regard to the most efficacious AAC solution for a given client. In spite of resource constraints, funding models that highlight the client's needs and requirements need to be found. Training and continuous professional development models that are practicable and meaningful to SLTs in the field are also urgently needed.

\section{Acknowledgements}

The authors would like to thank all the participants.

\section{Disclosure statement}

The authors report no conflict of interest. The authors alone are responsible for the content and writing of this paper 


\section{REFERENCES}

Alant, E. (1996). Augmentative and alternative communication in developing countries: Challenge of the future. Augmentative and Alternative Communication, 12, 1-12. doi:10.1080/07434619612331277428

Alant, E. (1999). Students with little or no functional speech in schools for students with severe mental retardation in South Africa. Augmentative \& Alternative Communication, 15(2), 8394.

Alant, E. (2005). Support-based AAC intervention. In E. Alant \& L. L. Lloyd (Eds.), Augmentative and alternative communication and severe disabilities: Beyond poverty (pp. 155-191). London, United Kingdom: Whurr.

American Speech-Language-Hearing Association, Ad Hoc Committee on the Scope of Practice in Speech-Language Pathology (2007). Scope of Practice in Speech-Language Pathology. Retrieved from http://www.asha.org/uploadedFiles/SP2007-00283.pdf

Barkham, M., Mellor-Clark, J., Connell, J., \& Cahill, J. (2006). A core approach to practicebased evidence: A brief history of the origins and applications of the CORE-OM and CORE System. Counselling and Psychotherapy Research, 6, 3-15.

doi:10.1080/14733140600581218

Beukelman, D. R., \& Mirenda, P. (2013). Augmentative and Alternative Communication: Supporting children and adults with complex communication needs (4th ed.). Baltimore, MD: Paul H. Brookes.

Binger, C., \& Light, J. (2007). The effect of aided AAC modeling on the expression of multisymbol messages by preschoolers who use AAC. Augmentative and Alternative Communication, 23, 30-43. doi:10.1080/07434610600807470 
Binger, C., Ball, L., Dietz, A., Kent-Walsh, J., Lasker, J., Lund, S.,...Quach, W. (2012).

Personnel roles in the AAC assessment process. Augmentative and Alternative Communication, 28, 278-288. doi:10.3109/07434618.2012.716079

Borg, J., Larsson, S., \& Östergren, P.-O. (2011). The right to assistive technology: for whom, for what, and by whom? Disability and Society, 26, 151-167. doi:10.1080/09687599.2011.543862

Braun, V., \& Clarke, V. (2006). Using thematic analysis in psychology. Qualitative Research in Psychology, 3, 77-101. doi:10.1191/1478088706qp063oa

Business Tech (2016). The astonishing number of South Africans who do not have medical aid. Retrieved from https://businesstech.co.za/news/lifestyle/129166/the-shocking-number-ofsouth-africans-who-do-not-have-medical-aid/

Costigan, F. A., \& Light, J. (2010). A review of preservice training in augmentative and alternative communication for speech-language pathologists, special education teachers, and occupational therapists. Assistive Technology: The Official Journal of RESNA, 22, 213-214. doi:10.1080/10400435.2010.492774

Dada, S., Horn, T., Samuels, A., \& Schlosser, R. W. (2016). Children's attitudes toward interaction with an unfamiliar peer with complex communication needs: Comparing highand low-technology devices. Augmentative and Alternative Communication, 32, 1-7. doi:10.1080/07434618.2016.1216597

Dada, S., Huguet, A., \& Bornman, J. (2013). The iconicity of picture communication symbols for children with English additional language and mild intellectual disability. Augmentative and Alternative Communication, 29, 360-373. doi:10.3109/07434618.2013.849753? 
Dada, S., Kathard, H., Tönsing, K., \& Harty, M. (2017). Severe Communication Disabilities in South Africa: Challenges and Enablers. In S. Halder \& L.C. Assaf (Eds.), Inclusion, Disability and Culture: An Ethnographic Perspective Traversing Abilities and Challenges (pp. 169-193). Switzerland: Springer International Publishing.

Department of Education. (2007). Guidelines to ensure quality education and support in special schools and special school resource centres. Pretoria, South Africa: Department of Education. Retrieved from http://www.google.co.za/url?sa=t\&rct=j\&q=\&esrc=s\&source=web\&cd=1\&ved=0CB8QFj AA\&url=http://www.thutong.doe.gov.za/resourcedownload.aspx?id=37716\&ei=NYaOVbj WOOKa7gbF1YP4DA\&usg=AFQjCNGnk392PP1WTa_kzhnTQzQCVJavA\&sig2=0s0vUo9xbff2zgsIy7gs2Q

Department of Education. (2010). Guidelines for inclusive teaching and learning. Pretoria, South Africa: Department of Education.

Department of Education. (2015). Report on the implementation of Education White Paper 6 on Inclusive Education. Pretoria, South Africa: Author.

Department of Health. (n.d.). Standardisation of provision of assistive devices in South Africa: a guideline for use in the public sector. Retrieved from http://uhambofoundation.org.za/new_wp/wpcontent/uploads/2016/06/standardisation_of_provision_of_assistive_devices_in_south_.pd Dietz, A., Quach, W., Lund, S. K., \& McKelvey, M. (2012). AAC assessment and clinical decision making: The impact of experience. Augmentative and Alternative Communication, 28, 148-149. doi:10.3109/07434618.2012.716079 
Dillman, D. A., Smyth, J. D., \& Christian, L. M. (2009). Internet, mail, and mixed-mode surveys. The tailored design method (3rd ed.) NJ: John Wiley \& Sons.

Field, A. (2013). Discovering statistics using IBM SPSS statistics. Sage.

Goldbart, J., Chadwick, D., \& Buell, S. (2014). Speech and language therapists' approaches to communication intervention with children and adults with profound and multiple learning disability. International Journal of Language \& Communication Disorders, 49, 687-701. doi:10.1111/1460-6984.12098

Golinker, L. (2009). Speech generating device funding for children. Exceptional Parent Magazine (Online), 39(9), 64-65. Retrieved from http://rettuniversity.org/wpcontent/uploads/2015/05/MEDICAID_funding_ep.pdf

Human Rights Watch (2015). “Complicit in exclusion”: South Africa's failure to guarantee an inclusive education for children with disabilities. Retrieved from https://www.hrw.org/report/2015/08/18/complicit- exclusion/south-africas-failureguarantee-inclusive-education-children.

Kathard, H., \& Pillay, M. (2013). Promoting change through political consciousness: A South African speech-language pathology response to the World Report on Disability. International Journal of Speech-Language Pathology, 15, 84-89. doi:10.3109/17549507.2012.757803

Kathard, H., Ramma, L., Pascoe, M., Jordaan, H., Moonsamy, S., Wium, A. M., ...Khan, N. B. (2011). How can speech-language therapists and audiologists enhance language and literacy outcomes in South Africa? (And why we urgently need to). South African Journal of Communication Disorders, 58, 59-71. Retrieved from http://sajcd.org.za/index.php/sajcd/article/view/27 
Koul, R. K., \& Corwin, M. (2011). Augmentative and alternative communication intervention for persons with chronic severe aphasia: Bringing research to practice. EBP Briefs, 6(2), 18. doi:10.1044/aac12.4.11

Light, J., \& McNaughton, D. (2015). Designing AAC research and intervention to improve outcomes for individuals with complex communication needs. Augmentative and Alternative Communication, 31, 85-96. doi:10.3109/07434618.2015.1036458

Lloyd, L. L., Fuller, D. R., \& Arvidson, H. H. (1997). Augmentative and alternative communication: A handbook of principles and practices.

Lucock, M., Leach, C., Iveson, S., Lynch, K., Horsefield, C., \& Hall, P. (2003). A systematic approach to practice-based evidence in a psychological therapies service. Clinical Psychology \& Psychotherapy, 10, 389-399. doi:10.1002/cpp.385

Marvin, L. A., Montano, J. J., Fusco, L. M., \& Gould, E. P. (2003). Speech-language pathologists' perceptions of their training and experience in using alternative and augmentative communication. Contemporary Issues in Communication Science and Disorders, 30, 76-83. doi:10.3109/07434610903322151

McCambridge, J., Witton, J., \& Elbourne, D. R. (2014). Systematic review of the Hawthorne effect: new concepts are needed to study research participation effects. Journal of clinical epidemiology, 67(3), 267-277. https://doi.org/10.1016/j.jclinepi.2013.08.015

McFadd , E. , \& Wilkinson , K . (2010). Qualitative analysis of decision making by speechlanguage pathologists in the design of aided visual displays. Augmentative and Alternative Communication, 26, 136 - 147 . doi:10.3109/07434618.2010.481089

McNaughton, D., \& Light, J. (2013). The iPad and mobile technology revolution: Benefits and challenges for individuals who require augmentative and alternative communication. 
Augmentative and Alternative Communication, 29, 107-116.

doi:10.3109/07434618.2013.784930

Mukhopadhyay, S., \& Nwaogu, P. (2009). Barriers to teaching non-speaking learners with intellectual disabilities and their impact on the provision of augmentative and alternative communication. International Journal of Disability, Development and Education, 56, 349362. doi:10.1080/10349120903306590

Newman, D. W., Kellett, S., \& Beail, N. (2003). From research and development to practice based evidence: Clinical governance initiatives in a service for adults with mild intellectual disability and mental health needs. Journal of Intellectual Disability Research, 47, 68-74. doi:10.1046/j.1365-2788.2003.00459.x

Nicolson, G. (2015, February 2). South Africa: where 12 million live in extreme poverty. Daily Maverick. Retrieved from https://www.dailymaverick.co.za/article/2015-02-03-southafrica-where-12-million-live-in-extreme-poverty/\#.WW4IZrZrHcc

Pillay, M., \& Kathard, H. (2015). Decolonizing health professionals' education: Audiology and speech therapy in South Africa. African Journal of Rhetoric, 7, 195-227. Retrieved from https://journals.co.za/content/aar_rhetoric/7/1/EJC172807

Schlosser, R. W., \& Raghavendra, P. (2004). Evidence-based practice in augmentative and alternative communication. Augmentative and Alternative Communication, 20, 1-21. doi.org/10.1080/07434610310001621083

Schlosser, R. W., Wendt, O., Angermeier, K. L., \& Shetty, M. (2005). Searching for evidence in augmentative and alternative communication: Navigating a scattered literature.

Augmentative and Alternative Communication, 21, 233-255.

doi:10.1080/07434610500194813 
Siu, E., Tam, E., Sin, D., Ng, C., Lam, E., Chui, M., Fong, A., Lam, L., \& Lam. C. (2010). A survey of augmentative and alternative communication service provision in Hong Kong. Augmentative and Alternative Communication, 26(4), 289-298. doi:

$10.3109 / 07434618.2010 .521894$

Soto, G., \& Yu, B. (2014). Considerations for the provision of services to bilingual children who use augmentative and alternative communication. Augmentative and Alternative Communication, 30, 83-92. doi:10.3109/07434618.2013.878751

South African Speech-Language-Hearing Association, Ethics and Standards Committee (2011). Code of ethics: Principles of ethics. Retrieved from http://www.mm3admin.co.za/documents/docmanager/55E836D5-3332-4452-BB059F12BE8DA9D8/00012416.pdf

Sutherland, D. E., Gillon, G. G., \& Yoder, D. E. (2005). AAC use and service provision: A survey of New Zealand speech-language therapists. Augmentative and Alternative Communication, 21(4), 295-307. doi: 10.1080/07434610500103483

Therrien, M. C. S., \& Light, J. (2016). Using the iPad to facilitate interaction between preschool children who use AAC and their peers. Augmentative \& Alternative Communication, 32, 163-174. doi:10.1080/07434618.2016.1205133

Thistle, J. J., \& Wilkinson, K. M. (2015). Building evidence-based practice in AAC display design for young children: Current practices and future directions. Augmentative and Alternative Communication, 31, 124-136. doi:10.3109/07434618.2015.1035798

Tönsing, K. M., \& Dada, S. (2016). Teachers' perceptions of implementation of aided AAC to support expressive communication in South African special schools: a pilot investigation. 
Augmentative and Alternative Communication, 32(4), 282-304.

doi.org/10.1080/07434618.2016.1246609

Van Niekerk, K., \& Tönsing, K. (2015). Eye gaze technology: A South African perspective.

Disability and Rehabilitation: Assistive Technology, 10, 340-346.

doi:10.3109/17483107.2014.974222

Van Niekerk, K., Dada, S., \& Tönsing, K. (2017). Influences on provision of assistive technology to young children in South Africa: Perspectives from rehabilitation professionals.

Manuscript submitted for publication.

Visagie, S., Eide, A. H., Mannan, H., Schneider, M., Swartz, L., Mji, G., .. MacLachlan, M. (2016). A description of assistive technology sources, services and outcomes of use in a number of African settings. Disability and Rehabilitation: Assistive Technology, Early

Online, 1-8. http://doi.org/10.1080/17483107.2016.1244293

World Health Organization. Assistive devices and technologies (2017). Retrieved from http://www.who.int/disabilities/technology/en/

Wormnaes, S., \& Malek, Y. A. (2004). Egyptian speech therapists want more knowledge about augmentative and alternative communication. Augmentative \& Alternative Communication, 20, 30-42. doi:10.1080/07434610310001629571

Wylie, K., McAllister, L., Davidson, B., \& Marshall, J. (2013). Changing practice: Implications of the world report on disability for responding to communication disability in underserved populations. International Journal of Speech-Language Pathology, 15, 1-13. doi:10.3109/17549507.2012.745164 


\section{Endnotes}

${ }^{1}$ The iPad, iPhone, iPod, and the iOS mobile operating system, are registered trademarks of Apple Inc., Cupertino, CA. www.apple.com.

${ }^{2}$ Android is a mobile operating system developed by Google Inc., Mountainview, CA. WWW.android.com

${ }^{3}$ In South Africa, SLTs qualify to practice after completing a 4-year graduate degree (professional Bachelor's degree). Currently, all graduate curricula in the field of SLT at the various universities include AAC training, and all SLT graduates may practice in the field of AAC (provided they judge themselves competent to do so).

${ }^{4}$ The Centre for AAC offers a multidisciplinary Master's degree in AAC in which qualified SLTs and other professionals can enroll to deepen their skills in AAC theory, research, and practice.

${ }^{5}$ Qualtrics Research Suite is a product of Qualtrics LLC, Provo, UT. www.qualtrics.com

${ }^{6}$ The GoTalk is a product of the Attainment Company Inc., Verona, WI.

Www.attainmentcompany.com

${ }^{7}$ The BIGmack, the Step by Step, Talking Bricks, and the iTalk2 are products of AbleNet Inc., Roseville, MN. www.ablenetinc.com

${ }^{8}$ Big Point is a product of Inclusive Technology of Oldham, United Kingdom. $\underline{\text { WwW.inclusive.co.uk }}$

${ }^{9}$ The Smart/Talk is a product of Advanced Multimedia Devices Inc., Farmingdale, NY. www.amdi.net

${ }^{10} \mathrm{Vmax}$ is a product of Tobii Dynavox, Pittsburgh, PA. www.tobiidynavox.com 
${ }^{11}$ Windows is a meta-family of graphical operating systems developed, marketed, and sold by Microsoft Corporation, Redmond, WA. www.microsoft.com 


\section{Appendix}

List of $\operatorname{iOS}^{1}$, Android $^{2}$, and Windows-based ${ }^{3}$ AAC Software and Applications Recommended by Participants

\begin{tabular}{|c|c|c|c|}
\hline Product & Function & Operating system & $\begin{array}{c}\text { \# of } \\
\text { participants } \\
\text { who } \\
\text { recommended } \\
\text { the product } \\
\end{array}$ \\
\hline $\begin{array}{l}\text { AAC Speech } \\
\text { Communicator }^{4}\end{array}$ & Communication & Android & 2 \\
\hline Alexicom $^{5}$ & Communication & iOS and Android & 2 \\
\hline $\begin{array}{l}\text { Boardmaker with } \\
\text { Speaking } \\
\text { Dynamically Pro }{ }^{6}\end{array}$ & Communication & Windows and iOS & 5 \\
\hline Clicker $^{7}$ & Literacy & Windows and iOS & 1 \\
\hline CommunicAide $^{8}$ & Communication & $\mathrm{iOS}$ & 1 \\
\hline $\begin{array}{l}\text { Communicate: By } \\
\text { Choice }^{9}\end{array}$ & Choice making practice & Windows & 2 \\
\hline Communicator $5^{10}$ & Communication & Windows & 1 \\
\hline E-triloquist $^{11}$ & Communication & Windows & 1 \\
\hline Gabby Tabs Lite ${ }^{12}$ & $\begin{array}{l}\text { Communication/ } \\
\text { Education }\end{array}$ & Android & 1 \\
\hline GoTalk Now $^{13}$ & Communication & $\mathrm{iOS}$ & 4 \\
\hline JABTalk $^{14}$ & Communication & Android & 1 \\
\hline LetMe Talk $^{15}$ & Communication & Windows and iOS & 4 \\
\hline Proloquo $2 \mathrm{Go}^{16}$ & Communication & $\mathrm{iOS}$ & 8 \\
\hline Small Talk Aphasia $^{17}$ & Communication & $\mathrm{iOS}$ & 1 \\
\hline Sono Flex ${ }^{18}$ & Communication & $\mathrm{iOS}$ & 2 \\
\hline Speak For Yourself ${ }^{19}$ & $\begin{array}{l}\text { Communication/ } \\
\text { Education }\end{array}$ & iOS & 1 \\
\hline Speech Button $^{20}$ & $\begin{array}{l}\text { Communication/ } \\
\text { Education }\end{array}$ & $\mathrm{iOS}$ & 1 \\
\hline TalkBoard $^{21}$ & Communication & $\mathrm{iOS}$ & 1 \\
\hline TalkTablet $^{22}$ & Communication & Android & 1 \\
\hline TaptoTalk $^{23}$ & Communication & Android and iOS & 5 \\
\hline The Grid $2^{24}$ & Communication & Windows & 3 \\
\hline $\begin{array}{l}\text { Tobii Dynavox } \\
\text { Compass }\end{array}$ & Communication & Windows and iOS & 3 \\
\hline $\begin{array}{l}\text { Touch and Speak: } \\
\text { Autism AAC }\end{array}$ & Communication & Android & 1 \\
\hline TouchChat $^{27}$ & Communication & $\mathrm{iOS}$ & 1 \\
\hline Verbally $^{28}$ & Communication & $\mathrm{iOS}$ & 1 \\
\hline
\end{tabular}




\section{Endnotes}

${ }^{1}$ The iPad, iPhone, iPod, and the iOS mobile operating system, are registered trademarks of Apple Inc., Cupertino, CA. www.apple.com.

${ }^{2}$ Android is a mobile operating system developed by Google Inc., Mountainview, CA. www.android.com

${ }^{3}$ Windows is a meta-family of graphical operating systems developed, marketed, and sold by Microsoft Corporation, Redmond, WA. www.microsoft.com

${ }^{4}$ AAC Speech Communicator is an application developed by Vidmantas Zemleris wWw.zemleris.com

${ }^{5}$ Alexicom is a product of Alexicom Tech, Phoenix, AZ. www.alexicomtech.com

${ }^{6}$ Boardmaker with Speaking Dynamically Pro is a software product of Mayer-Jonhson (of the Tobii Dynavox Family), Pittsburgh, PA. www.mayer-johnson.com

${ }^{7}$ Clicker is a software product of Crick Software, Northampton, United Kingdom. www.cricksoft.com

${ }^{8}$ CommunicAide is a product of by Hope 4 Speech Associates, P.C. www.hope 4 speech.com/

${ }^{9}$ Communicate: By Choice is a product of Widgit, USA. www.widgit.com

${ }^{10}$ Communicator 5 is a software product of Tobii Dynavox, Pittsburgh, PA. Www.tobiidynavox.com

${ }^{11}$ E-triloquist is a software product of E-triloquist. www.etriloquist.com

${ }^{12}$ Gabby Tabs Lite is a product of Tech Unlimited, LCC, New Ulm, MN. www.facebook.com/TULLC/

${ }^{13}$ GoTalk Now is a product of the Attainment Company Inc., Verona, WI. Www.attainmentcompany.com 
${ }^{14} \mathrm{JABT}$ alk is a product of JABstone. www.jabstone.com

${ }^{15}$ LetMe Talk is a product of AppNotize, UG, Berlin, Germany. www.letmetalk

${ }^{16}$ Proloquo2Go is a product of AssitiveWare, Amsterdam, The Netherlands. www.assistiveware.com

${ }^{17}$ Small Talk Aphasia is a product of Lingraphica, Princeton, NJ. www.aphasia.com

${ }^{18}$ Sono Flex (iOS application) is a product of Tobii Dynavox, Pittsburgh, PA. www.tobiidynavox.com

${ }^{19}$ Speak For Yourself is a product of Speak for Yourself LLC, USA. www.speakforyourself.org

${ }^{20}$ Speech Button AAC is a product of Wipitup, USA. www.wipitup.com

${ }^{21}$ TalkBoard is a product of Mark Ashley, UK. www.mashley.net

${ }^{22}$ TalkTablet is a product of Gus Communication Devices, Scottsdale, AZ. www.talktablet.com

${ }^{23}$ TapToTalk is discontinued as a product. www.taptotalk.com

${ }^{24}$ The Grid 2 is a software product of Smartbox Assistive Technology, Malvern, WR. www.smartbox.com

${ }^{25}$ Tobii Dynavox Compass is a product of Tobii Dynavox, Pittsburgh, PA. Www.tobiidynavox.com

${ }^{26}$ Touch and Speak: Autism AAC is a product Indigo Kids Limited. www1.indigo-app.com

${ }^{27}$ TouchChat is a product of TouchChat. www.touchchatapp.com

${ }^{28}$ Verbally is a product of Intuary Inc. www.verballyapp.com 